\title{
ARTICLE
}

\section{An Analysis of Tritium Concentration in Urine Samples as a Function of Time after Intake}

\author{
Hee Geun KIM*, Tae Young KONG, Woo Tae JEONG, Seok Tae KIM \\ Korea Electric Power Research Institute, 103-16 Munji-dong, Yuseong-gu, Daejeon, 305-380, Korea
}

\begin{abstract}
In pressurized heavy water reactors, workers who enter radiation controlled areas must submit urine samples to health physicists after radiation work; these samples are then used to monitor internal radiation exposure from tritium intake. But this procedure assumes that the samples submitted accurately represent tritium concentration inside the body at equilibrium. According to both technical reports from the International Commission on Radiological Protection and experimental results from Canadian nuclear utilities, tritium inside the body generally reaches equilibrium concentration after several hours of intake. In practice, urine samples can be submitted either before the 2-hour mark or after several hours of radiation work because of the numerous tasks workers must perform and their frequent entry during nuclear power plant maintenance. In this paper, tritium concentration in workers' urine samples was measured as a function of time submitted after radiation work. Based on the measurement results, changes in the tritium concentration inside the body and its effect on internal dose assessment were then analyzed. As a result, it was found that tritium concentration reaches equilibrium concentration before the 2-hour mark for most workers' urine samples.
\end{abstract}

KEYWORDS: tritium concentration, urine sample, time after intake, submission time, internal dose assessment, pressurized heavy water reactor

\section{Introduction}

In a pressurized heavy water reactor (PHWR), workers who enter radiation controlled areas where tritium exists in the air are likely to have internal radiation exposure by tritium inhalation. Thus, workers in PHWRs must submit urine samples to health physicists after radiation work for assessment of their internal dose of tritium. ${ }^{1)}$ In Korean nuclear power plants (NPPs), a liquid scintillation counter (LSC) is typically used to measure tritium concentration in radiation workers' urine samples after mixing with scintillation cocktails. ${ }^{2-4)}$ The committed effective dose is then calculated by the product of tritium concentration inside the body based on monitoring results and its dose conversion coefficient. ${ }^{2,5,6)}$

For internal dose assessment, it is necessary to assume that urine samples are submitted when tritium concentration inside the body has reached equilibrium; that is, the urine samples submitted are representative samples whose tritium concentration does not differ from those of urine samples collected within the next 24 hours or other specified periods. ${ }^{67)}$ According to technical reports from the International Commission on Radiological Protection (ICRP), Canadian nuclear utilities and the standard procedures of the Korea Hydro and Nuclear Power Corporation (KHNP), tritium inside the body generally reaches equilibrium concentration after approximately 2 hours of intake. ${ }^{2,5,6)}$ If urine samples are submitted before tritium concentration inside the body reaches equilibrium, they cannot be representative samples and any internal dose assessment based on monitoring results of these samples is

*Corresponding Author, Tel. +82-42-865-5467, FAX.

+82-42-865-5412, E-mail: hkkim@kepri.re.kr incorrect. Thus, in Korean NPPs, workers should submit urine samples after equilibrium following radiation work. ${ }^{2)}$

In practice, workers can submit urine samples either before the 2-hour mark or after several hours of radiation work because of the numerous tasks they must perform and their frequent entry during NPP maintenance. In this paper, tritium concentration was measured as a function of time for urine sample submission after radiation work. Based on these measurement results, changes in the tritium concentration inside the body and its effect on internal dose assessment were analyzed.

\section{Tritium Concentration in the Body}

Knowledge of the average tritium distribution in time and space (in body water and soft tissue) is a prerequisite for dosimetry. Once inside the body, the tritium diffuses freely and rapidly across the membrane of soft tissue, equilibrating throughout the total body water pool. Tritiated water (HTO) is distributed in the intracellular and extracellular body water; consequently, tritium retention in the body follows the biokinetics of body water. The concentration in urine, a few hours post-exposure usually after an initial voiding, is expected to be the same as in other body fluids.

The standardization of tritium dosimetry is based on a calculation of soft tissue dose that assumes uniform tritium distribution throughout the soft tissue of the body. ICRP-56 recommends that one should assume that internalized tritium is completely and instantaneously absorbed by and mixed rapidly with the total body water. Accordingly, at all times, the concentration in urine and body fluids is assumed to be in equilibrium with water in the body. The uniform 
concentration of tritium in the body after tritium intake results in the radiation dose being uniformly distributed throughout all body tissues. ${ }^{8)}$

According to experimental results from the Canadian nuclear utilities, tritium inside the body generally reaches equilibrium concentration after approximately 2 hours of inhalation, although some minor differences occur at the initial levels. ${ }^{8-12)}$ Analysis of experimental results from Canadian nuclear utilities is presented in Fig. 1. ${ }^{10-12)}$

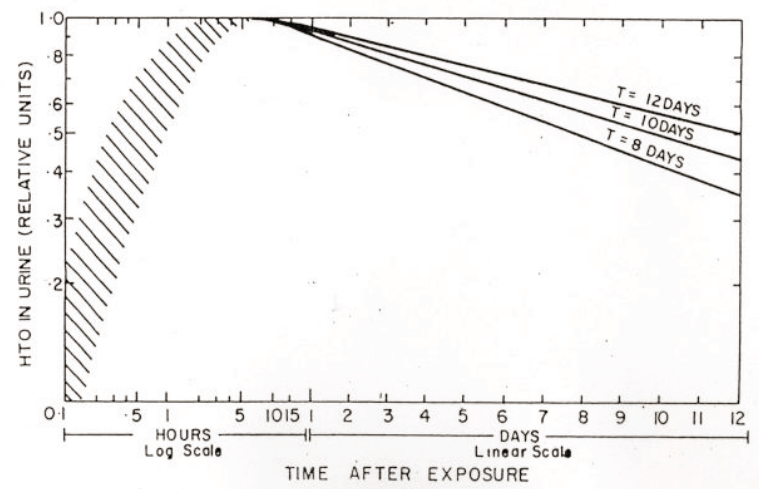

Fig. 1 Change of tritium concentration in urine after exposure at Canadian NPPs. ' $\mathrm{T}=12,10,8$ DAYS' indicates the biological half lives of tritium.

\section{Internal Dose Assessment for Tritium}

The procedure for radiation protection in Korean NPPs provides that urine samples should be submitted after 2 hours of radiation work. ${ }^{2,3)}$ Furthermore, according to this procedure, urine samples should be submitted 1) after an appointment as a radiation worker or frequent visitor and upon its termination; and 2) after access to radiation controlled areas. For radiation workers with a recent tritium concentration of more than $37 \mathrm{~Bq} / \mathrm{cc}$, urine samples should be submitted more than once within 14 days. Radiation workers who were asked to submit urine samples before and after radiation work in a radiation work permit should submit urine samples before and after radiation tasks. Finally, radiation workers whose tritium concentration is more than $1,850 \mathrm{~Bq} / \mathrm{cc}$ are required to submit their urine samples more than once a week until tritium concentration is reduced to lower than $740 \mathrm{~Bq} / \mathrm{cc}^{2,3)}$

Basically, the committed effective dose of tritium is calculated by Eq. (1) for radiation workers and frequent visitors. $^{2,3,6,13,14)}$ Internal dose assessment for tritium is currently conducted only in case a radiation worker's tritium concentration is more than the recoding level, or over $37 \mathrm{~Bq} / \mathrm{cc}^{2,3,6,13,14)}$

$$
E=0.292 \times \frac{1}{37} \times 10^{-2} \times 0.733 \times \frac{\left(C_{1}+C_{2}\right)}{2} \times T(\mathrm{mSv})(1)
$$

where $E$ is the effective dose of tritium ( $\mathrm{mSv}), T$ is the time interval (day) between the previous submission date of a urine sample $\left(T_{1}\right)$ and the present submission date of a urine sample $\left(T_{2}\right), C_{1}$ is the previous tritium concentration in a urine sample $(\mathrm{Bq} / \mathrm{cc})$, and $C_{2}$ is the present tritium concentration in a urine sample $(\mathrm{Bq} / \mathrm{cc})$. Furthermore, " $0.292 "$ is the conversion factor for dose equivalent rate from tritium beta energy ( $\mathrm{mrem} \cdot \mathrm{L} / \mathrm{Bq} \cdot \mathrm{day})$, " 0.733 " is the conversion factor for soft tissue of reference man, and " $1 / 37$ " is the conversion of units from $\mu \mathrm{Ci} / \mathrm{L}$ to $\mathrm{Bq} / \mathrm{cc}$. The detailed process of dose assessment for measurement data of tritium concentration were demonstrated in International Atomic Energy Agency (IAEA) reports and other papers. $^{6,13,15)}$

In the case of workers who must move to other NPPs or cancel their assignment as radiation workers, the committed effective dose of tritium is calculated by Eq. (2). ${ }^{2,3,6,13,14)}$

$$
E=3.09 \times \frac{1}{37} \times 10^{-2} \times C_{3}(\mathrm{mSv})
$$

where $C_{3}$ is the final tritium concentration in a urine sample (Bq/cc). In addition, "3.09" is the conversion factor of committed effective dose for radiation workers who completed the task permanently or are cancelled as a radiation worker. For example, if the measurement result of tritium activity in urine is $370 \mathrm{~Bq} / \mathrm{cc}(10 \mu \mathrm{Ci} / \mathrm{L})$ and the worker did not conduct the additional tasks, the effective dose can be calculated as $0.31 \mathrm{mSv}$ by Eq. (2).

\section{Experiments on Tritium Concentration}

Workers who enter radiation controlled areas or participate in radiation work during PHWR maintenance period were selected for tritium measurement. In particular, 15 volunteers who had an acute intake of tritium and who did not have any radiation exposure by tritium more than 1 week after radiation work such as man-way opening of a steam generator were among the participants. Volunteers who submitted urine samples were notified prior to the

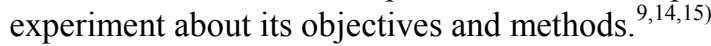

It was requested that urine samples be periodically submitted before radiation work and after 30 minutes, 2 hours, 8 hours, 1 day, 3 days, and 7 days of radiation work. Tritium concentration levels were classified into three categories: 1 - $37 \mathrm{~Bq} / \mathrm{cc}, 38$ - $370 \mathrm{~Bq} / \mathrm{cc}$, and over 370 $\mathrm{Bq} / \mathrm{cc}$. LSC was used to measure the concentration of tritium in the urine samples.

\section{Analysis of the Excreted Concentration}

Change of tritium concentration inside the body for 15 volunteers was analyzed as a function of time for urine sample submission after radiation work. As a result, tritium concentration typically reached equilibrium between after 2 hours and after 1 day of tritium inhalation. The tritium concentration then decreased slowly, although there were some minor differences among individual workers., ${ }^{9,15)}$ Changes in tritium concentration inside the body depending 
Table 1 Tritium concentration in urine samples as a function of time of submission at Korean PHWRs (Unit: Bq/cc)

\begin{tabular}{|c|c|c|c|c|c|c|c|}
\hline Name & Right Before & Right After & After 2 hours & After 8 hours & After 1 day & After 3 days & After 7 days \\
\hline $\mathrm{A}$ & 15 & 123 & 207 & 206 & 208 & 168 & 133 \\
\hline $\mathrm{B}$ & 0 & 10 & 56 & 55 & 54 & 44 & 26 \\
\hline $\mathrm{C}$ & 14 & 82 & 185 & 208 & 218 & 168 & 128 \\
\hline $\mathrm{D}$ & 14 & 51 & 127 & 122 & 121 & 100 & 61 \\
\hline E & 2 & 160 & 173 & 166 & 168 & 134 & 84 \\
\hline $\mathrm{F}$ & 0 & 7 & 9 & 7 & 6 & 6 & 5 \\
\hline G & 0 & 0 & 1 & 2 & 2 & 2 & 1 \\
\hline $\mathrm{H}$ & 0 & 1 & 1 & 2 & 2 & 1 & 1 \\
\hline I & 0 & 8 & 32 & 33 & 31 & 23 & 15 \\
\hline $\mathrm{J}$ & 0 & 2 & 4 & 11 & 9 & 6 & 48 \\
\hline K & 0 & 3 & 12 & 12 & 13 & 9 & 6 \\
\hline $\mathrm{L}$ & 2 & 5 & 14 & 13 & 11 & 11 & 9 \\
\hline M & 6 & 7 & 11 & 10 & 9 & 8 & 5 \\
\hline $\mathrm{N}$ & 0 & 61 & 97 & 85 & 82 & 58 & 49 \\
\hline $\mathrm{O}$ & 0 & 1 & 4 & 2 & 2 & 0 & 2 \\
\hline
\end{tabular}

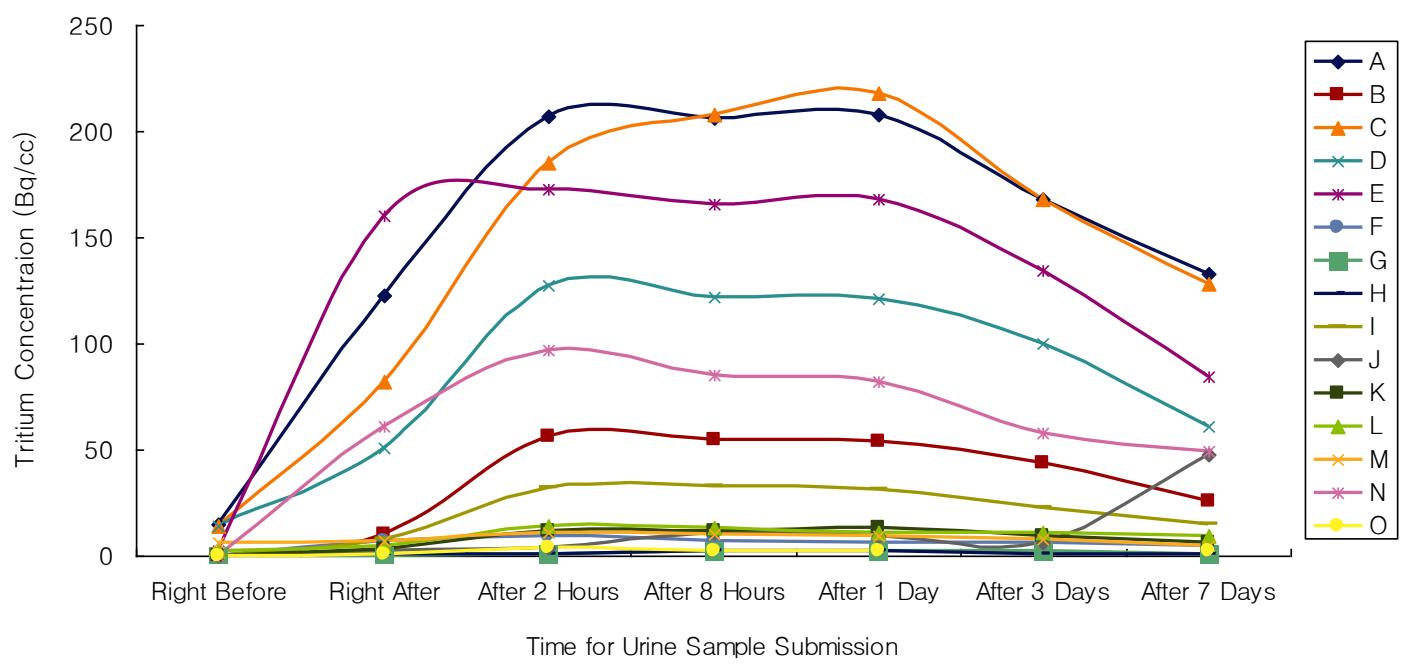

Fig. 2 Change of tritium concentration for radiation workers at Korean NPPs

on time elapsed after radiation work when urine samples were submitted is shown in Table 1 and Fig. 2. In case of volunteer ' $C$,' the tritium concentration at after 2 hours and at after 8 hours indicated the minor differences between the two within approximately $10 \%$. Thus, it is can be determined that the tritium inside the body reaches equilibrium of concentration after approximately 2 hours of intake. It was also found that if the urine sample is submitted less than 1 day after radiation tasks, its tritium concentration is similar with that at after 2 hours. On the other hand, the tritium concentration of volunteer ' $\mathrm{J}$ ' increased sharply at after 7 days because he entered the radiation controlled area again and had an additional intake of tritium.

The experimental results from this study also were in line with those of other experiments from Canadian nuclear utilities. Thus, the current procedure for radiation protection in Korean NPPs which requires submission of urine samples after 2 hours of radiation work is regarded as a reasonable guideline and it is concluded that urine samples submitted according to this procedure are representative samples.

Furthermore, it was found that the effective half-life of tritium for Korean NPP workers is shorter than that suggested by the ICRP $\left(\mathrm{T}_{1 / 2}=7.43 \pm 2.22\right.$ day for Korean at a confidence level of $90 \%, \mathrm{~T}_{1 / 2}=10$ day for ICRP 
Reference man). This prevents from the possible underestimation of effective dose depending on the various time of urine sample submission after radiation work. The detailed results of effective half-life for Korean due to intake of tritium were demonstrated in the KHNP report and papers. ${ }^{13-17)}$

\section{Conclusion}

In this study, uncertainty of time for urine sample submission and internal dose assessment for tritium were evaluated by analyzing measurement results in relation to the time of urine sample submission for radiation workers in Korean PHWRs. After comparing these results with those of technical papers and reports, the results from this study were found to be consistent with those of other experiments from Canadian nuclear utilities confirming that tritium inside the body reaches equilibrium concentration after approximately 2 hours of intake.

Thus, it is regarded that the procedure in Korean NPPs meets the technical criteria for urine sample submission and urine samples submitted by radiation workers are the representative samples reflecting that tritium concentration inside the body has reached equilibrium. Finally, this study confirms that both measurement of tritium concentration and internal dose assessment for tritium in Korean NPPs are reliable, eliminating concern about the uncertainty of internal dose assessment for tritium depending on the time of urine sample submission.

\section{Acknowledgment}

This research was carried out with the financial support of Korea Hydro \& Nuclear Power Corporation.

\section{References}

1) Korea Hydro and Nuclear Power Co., Final Safety Analysis Report for the Wolsong Nuclear Power Plants Units 3 and 4, (2000).

2) Korea Hydro and Nuclear Power Co., Standard Procedure in Nuclear Power Plants: Measurement and Assessment of Internal Dose, Radiation-06, (2008).

3) Korea Hydro and Nuclear Power Co., Procedure for Management of Occupational Radiation Exposure at Wolsong NPPS Unit 1, Revision 7, Radiation 0-60105, (2006).

4) Korea Hydro and Nuclear Power Co., Performance Procedure for Liquid Scintillation Counting at Wolsong NPPS Unit 2, Revision 6, Radiation-12, (2007).
5) International Commission on Radiological Protection, Individual Monitoring for Internal Exposure of Workers, Replacement of ICRP Publication 54, ICRP Publication 78, Annals of the ICRP, Pergamon Press, Oxford, UK, (1997).

6) International Atomic Energy Agency, Methods for Assessing Occupational Radiation Doses Due to Intakes of Radionuclides, Safety Report Series No. 37, (2004).

7) D. W. Whillans, K. S. Thind, Internal Dosimetry for Short-Range Emitters, Health Physics Society 1995 Summer School (Radiation Protection at Nuclear Reactors), Medical Physics Publishing, Madison, Wisconsin, (1995).

8) H. G. Kim, S. H. Linauskas, A. Trivedi, R. B. Richardson, Technical Basis for Tritium Dosimetry in Korean CANDU reactors, AECL Technical Report, RC-1554. (1996).

9) Korea Electric Power Research Institute, Review Paper for Technical Supports: Change of Tritium Concentration inside Body depending on Time of Urine Sample Submission, (2005).

10) R. V. Osborne, "Absorption of Tritiated Water Vapor by People," Health Physics, 12, 1527-1537 (1996).

11) J. R. Johnson, "The Estimation of the Effective Dose Equivalent from Tritiated Water Exposures Using Tritium Concentration in Urine," Radiation Protection Dosimetry, 2, 245-247 (1982).

12) B. Wolodarsky, "OPG Tritium Dosimetry," Proc. of $O P G$ Radiation Protection Workshop, 2005.

13) H. G. Kim, T. Y. Kong. "Analysis of Metabolism and Effective Half-life for Tritium Intake of Radiation Workers at Pressurized Heavy Water Reactor," J. Radiation Protection, 34[2], 87-94 (2009).

14) Korea Hydro and Nuclear Power Co., Final Report: Development on the Verification System of Internal Dose Measurement and Assessment, I05NJ14, (2006).

15) H. G. Kim, T. Y. Kong, W. T. Jeong, S. T. Kim, “An Internal Tritium Concentration Analysis in Urine Samples as a Function of Submission Time after Airborne Tritium Intake at Korean Pressurized Heavy Water Reactor," J. Radiation Protection, 34[4], 184-189 (2009).

16) H. G. Kim, "Review of Metabolism and Effective Dose for Tritium," Proc. of Korean Association of Radiation Protection, April (2001).

17) H. G. Kim, H. S. Lee. "Review of Tritium Metabolism based on the Measurement Results for Korean Nuclear Power Plants," Proc. of Korean Nuclear Society, May (2001). 